Research Article

\title{
Development of Downscaled Climate Projections: A Case Study of the Red River Basin, South-Central U.S.
}

\author{
Darrian Bertrand $\mathbb{D}^{1}$ and Renee A. McPherson $\mathbb{D D}^{1,2}$ \\ ${ }^{1}$ Department of Geography and Environmental Sustainability, University of Oklahoma, Norman 73019, USA \\ ${ }^{2}$ South Central Climate Adaptation Science Center, Norman 73019, USA \\ Correspondence should be addressed to Darrian Bertrand; dmbertra@ncsu.edu
}

Received 1 March 2019; Revised 27 May 2019; Accepted 5 September 2019; Published 22 October 2019

Guest Editor: Jayant K. Routray

Copyright (C) 2019 Darrian Bertrand and Renee A. McPherson. This is an open access article distributed under the Creative Commons Attribution License, which permits unrestricted use, distribution, and reproduction in any medium, provided the original work is properly cited.

\begin{abstract}
Climate models provide information that resource managers, policy makers, and researchers can use when planning for the future. While this information is valuable in the broad sense, the low spatial-resolution often lacks local details that resource managers and decision makers need to plan for their communities. Therefore, statistically downscaled climate projections provide a highresolution output and offer local information that is more beneficial than coarse-resolution global climate model output. In the Red River Basin, located in the south-central U.S., this detailed information is used to develop long-term water plans. This area is prone to drought conditions and heavy precipitation events, and studies have consistently estimated that this will continue in the future. This paper introduces a dataset of statistically downscaled climate projections of daily minimum and maximum temperature and daily precipitation that is a useful tool for studies regarding climatological and hydrological aspects in the region. The dataset was created using two quantile mapping techniques to downscale the CCSM4, MPI-ESM-LR, and MIROC5 model outputs to a 0.1-degree spatial resolution. Furthermore, we describe the added value of coproduction of knowledge between climate scientists and end users, or in this case impacts modelers and decision makers, for creating climate projections that can be used for climate risk assessments. A case study of the data's development and application is provided, detecting the mean daily changes in temperature and precipitation through the end of the century in the Red River Basin for two representative concentration pathways. After applying the users' inputs to develop the datasets, results for this example estimate an increase in mean daily precipitation in the eastern portion of the basin and as much as a $15 \%$ decline in the west by the end of the century. Furthermore, mean daily temperature is expected to rise across the entire basin in all scenarios by up to $6-7^{\circ} \mathrm{C}$.
\end{abstract}

\section{Introduction}

As the global climate changes, numerical projections from climate models provide information that aids resource managers, policy makers, and researchers in planning for the future $[1,2]$. Although water resource managers and other decision makers can view global climate models (GCMs) for basic information, the associated low spatial-resolution output lacks the local information that they need to plan for their community [2] and implement into hydrologic models [3]. Therefore, high-resolution climate projections that are either model-generated in high resolution (less common) or are downscaled to high resolution (more common) are more useful to these local managers. For example, in the Red River
Basin, located in the south-central United States (U.S.), this detailed climate information helps those who make longterm (e.g., 50 years) water plans. In many cases, stakeholders who desire to use downscaled climate projections may choose one dataset, looking for the "best" or "most likely" option, rather than recognizing that climate risk assessment requires them to acknowledge uncertainties and instead use a suite, or ensemble, of datasets.

This paper discusses the creation of downscaled datasets that include historical and future projections of daily minimum and maximum temperature and daily precipitation. The intent was to develop an ensemble of projections that stakeholders in the Red River Basin could use for climate risk assessment. During the process of 
developing the datasets, we found that some methods provided results that we deemed unacceptable for our users and some choices within the method implementation were less appropriate than other choices for certain variables. We used what we learned to begin developing a new ensemble of climate projections for the entire south-central U.S.; yet, once users have access to one set of projections, they are reluctant to update to another set as science evolves. We will discuss some of these nuances for the case study of building an ensemble of projections for the Red River Basin in the south-central U.S. While we detail the methods for developing the dataset, we highlight some of the issues that arise as the climate science community works with those in other disciplines, including modelers and decision makers.

Before we delve into statistical downscaling and its uses, it is important to discuss GCMs, which are numerical models that represent atmospheric and oceanic processes [4] and can offer a large-scale view of future climate conditions, such as projected temperature and precipitation, under different representative concentration pathways (RCPs). The RCPs serve as scenarios of various radiative forcing trajectories from anthropogenic greenhouse gas emissions and changes in land cover [5]. Moss et al. [5] discussed the four RCPs-RCP 2.6, RCP 4.5, RCP 6.0, and RCP 8.5--where RCP 2.6 represents a scenario where radiative forcing peaks at $3.1 \mathrm{~W} / \mathrm{m}^{2}$ and the concentration of greenhouse gases reaches 490 parts per million in 2100 and then decreases, and RCP 8.5 represents a scenario with more than $8.5 \mathrm{~W} / \mathrm{m}^{2}$ of radiative forcing and a concentration of greenhouse gases that exceeds 1,370 parts per million by 2100 .

Although GCMs provide an overall depiction of possible future conditions, they do not take local processes into account, having a coarse-resolution range of 50 to 600 kilometers, depending on the model [4, 6-9]. These local processes can include mountain meteorology and land-sea interactions [6]. Other GCM limitations include biases in rainfall intensity, responses to climate forcing, natural variability range, and simulated precipitation with a shortfall in convection and across mountainous areas $[10,11]$. Downscaling can correct some of these GCM biases [11, 12] and allow us to project local changes in the future in greater detail where there are no observations to interpolate. Furthermore, downscaling provides a higher spatial resolution that allows local decision makers and resource managers to make more informed decisions about their area and to understand local phenomena to a higher degree [13].

Thrasher et al. [2] provided an example of the significance of downscaled climate projections to resource managers and decision makers. The spatial resolution of the projections offered enough detail to determine the changes in the freezing line in mountainous regions, relating to the amount of melting snowpack that affects the water supply. Resource managers also can learn about how their area may be affected by drought, causing them to change their community's water plans and usage of the water supply [14]. In addition, knowing how their region's climate is expected to change may alter food production areas, causing alteration in land use [15], especially where crops are rainfed.
Downscaled climate projections provide more localized information than GCMs through high-resolution data for applications by decision makers and can help them to create better drought and water resource management strategies [16]. For example, Bertrand and McPherson [17] use the dataset described in this study to determine that severe drought is expected to increase in the western Red River Basin and heavy precipitation events are projected to increase in the eastern basin, especially by the end of the $21 \mathrm{st}$ century under RCP 8.5. The high-resolution data allowed them to identify an east-west gradient in these changes that follows the natural precipitation gradient of the region.

\section{Study Domain}

This study focuses on a case study in the Red River Basin of the South (hereafter Red River Basin), with headwaters in far eastern New Mexico (Figure 1), flowing west to east through Texas, Oklahoma, and Arkansas, and exiting into the Mississippi River in Louisiana. The basin covers $239,361 \mathrm{~km}^{2}$ and crosses a west-to-east gradient of precipitation with average yearly rainfall totals of approximately 500 to 1300 millimeters (20 to 50 inches). Because of this moisture gradient, the Red River Basin is home to many different ecoregions, from the High Plains in the west to the South Central Plains in the east [18].

This basin is vital for the area's drinking water supply and recreational and cultural activities [19]. However, because the basin benefits multiple states and metropolitan cities, such as Fort Worth, TX, and Oklahoma City, OK, there have been disagreements regarding water rights in this basin. Oklahoma, Texas, Arkansas, and Louisiana signed a water compact in 1978 to share the water resource fairly [20]; however, because Texas had been routinely exceeding its allotment of water, the Oklahoma Legislature restricted the state's apportioned water to remain within state boundaries in 2002, excluding Texas from any option to buy water from Oklahoma [21]. This new statute, Title 82-1B, upset decision makers in Texas because Tarrant County, including Fort Worth, previously bought water from Oklahoma. The issue eventually rose to a legal case that was brought before the U.S. Supreme Court-Tarrant Regional Water District vs. Hermann [22] - that wished to declare Oklahoma's new law as unconstitutional under interstate commerce laws. The case was dismissed, however, allowing Oklahoma to determine how to use its apportioned water.

Similarly, in 2016, a water rights issue between the City of Oklahoma City and both the Choctaw Nation of Oklahoma and Chickasaw Nation was resolved. This dispute arose in 2011, during a period of extreme drought in Oklahoma and Texas, when officials in Oklahoma City purchased rights to water in Sardis Lake, a reservoir in southeast Oklahoma that is within tribal boundaries of the Choctaw Nation of Oklahoma. Both tribes had views of water rights that conflicted with those of Oklahoma City, but all governments came to an agreement that allowed the State of Oklahoma to manage the water supply while ensuring that the tribes continued to have a voice in water resource and conservation issues for the region. These disagreements are important 


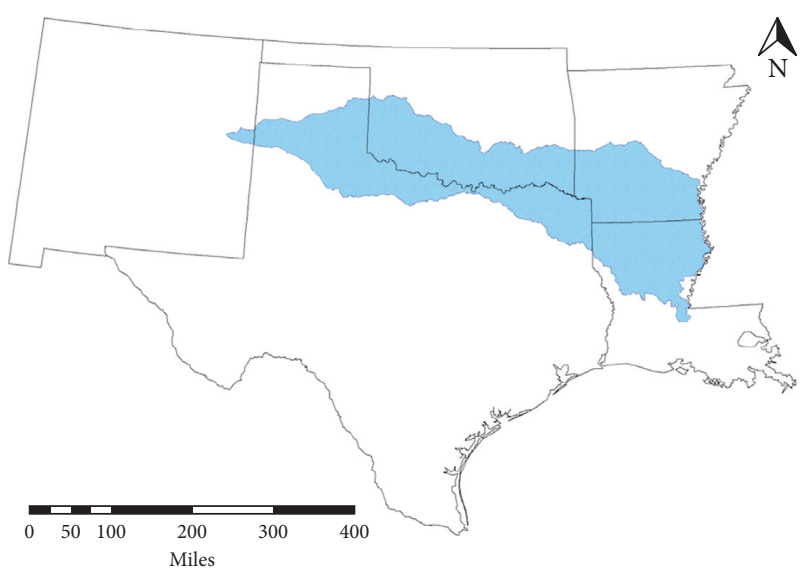

Figure 1: Red River Basin.

examples of the extremes that communities under pressure from water stress will undertake to gain or maintain their rights to water. With drought ravaging the U.S. Southern Plains in the decade of the 2010s, states have been forced to look for new water resources or reduce water use. Therefore, precipitation, temperature, and streamflow projections have become of important interest to water planners in the basin.

\section{Data}

3.1. Introduction to the Dataset. This study employs an ensemble of statistically downscaled, high-resolution climate projections that were generated by the Geophysical Fluid Dynamics Laboratory of the National Oceanic and Atmospheric Administration (NOAA) and disseminated by the South Central Climate Adaptation Science Center of the U.S. Geological Survey. A postdoctoral associate (supervised by the second author of this paper) of the South Central Climate Adaptation Science Center worked with scientists and engineers at the NOAA lab to produce the datasets. One purpose of the ensemble was to examine the representativeness of the dataset to aid water resource managers in the Red River Basin with their long-term water plans. The ensemble of historical and future climate data was generated by statistically downscaling output from three representative GCMs using empirical relationships between a predictor, or large-scale climate variable, and a predictand, or local-scale surface variable, by diverse techniques [23]. Appropriate transfer functions, described below, were used to link the predictor and the predictand. Statistical downscaling was a better option for this study, compared to dynamical downscaling, because it allowed us to create projections for multiple models and scenarios without being as computationally demanding and expensive.

Downscaled daily surface maximum and minimum temperatures and daily precipitation were computed for historical and future periods using over 3600 grid points throughout the region. The historical outputs were trained from an observational dataset from Livneh et al. [24] that originally included daily minimum and maximum temperature and daily precipitation data from 1915-2011 with a 1/16-degree resolution. From these data, a time frame of
January $1^{\text {st }}, 1961$, to December $31^{\text {st }}, 2005$, was selected and the data were downscaled to $0.1^{\circ}$, which is sufficient spatial resolution to capture regional climatic differences but is larger than the microscale so that we are not capturing noise. The downscaled projections included a time frame of 1961-2005 for the historical period, which is a common definition of the historical period when using CMIP5 models, and 2006-2099 for the future period, seeking results for the end of the $21^{\text {st }}$ century. This dataset allowed us to view projections in the future directly or to analyze change maps and examine future changes in the region.

To force the projections on the large scale, three GCMs were chosen from the Coupled Model Intercomparison Project Phase 5 (CMIP5) [25]: the low-resolution version of the Max Planck Institute's Earth System Model (MPI-ESMLR) [26], the Community Climate System Model (CCSM4) [27], and the fifth version of the Model for Interdisciplinary Research on Climate (MIROC5) [28]. The CCSM4 model has a resolution of $0.9^{\circ}$ by $1.3^{\circ}$ and couples the atmosphere, ocean, land surface, and sea ice, and the sixth realization was used for this study, which spans from 1850 to 2005. For the MPI-ESM-LR model with a 1.9-degree resolution, the $\mathrm{r} 1$ realization was used, which has a time frame from 1880 through 2005; future simulations included natural forcings but excluded volcanic aerosols after 2005. The $\mathrm{r} 1$ realization was used for the MIROC5 model with a resolution of $1.4^{\circ}$. In addition, the first version of the perturbed physics model was used for all models.

Only three GCMs were selected due to computational demand of downscaling and running the data through the VIC model. Although the end users wanted only one model, our team compromised on three so as to include some range of uncertainty. For climate risk assessment, it is important to include multiple scenarios, multiple GCMs, and multiple downscaling techniques (e.g., Wootten [29]) to represent uncertainties that can affect decision making. These models were selected based on their historical performance from the evaluation of Sheffield et al. [30], which included consideration of model biases in seasonal temperature and precipitation over North America and central North America. We subjectively selected the final three GCMs because 1) they have relatively smaller biases compared to the full suite of CMIP5 models and 2) they span a range of one standard deviation above and below the ensemble mean in both temperature and precipitation (Figures 2(a) and 2(b)), thus incorporating much of the uncertainty. Additionally, the climate sensitivity of the models was included in the overall selection process [31] (Figure 2(c)). For example, MIROC5, CCSM4, and MPI-ESM-LR represent the lower 50\% mean, and upper $50 \%$ of the distribution of model sensitivities, showing that these models are representative of the general spread of the GCMs and are not on the extreme end of the spectrum.

3.2. Quantile Mapping Approaches. After model selection, we selected three of the four available RCP scenarios (RCP 2.6, RCP 4.5, and RCP 8.5) because they represent the full range of existing scenarios. Using these for each of the three 


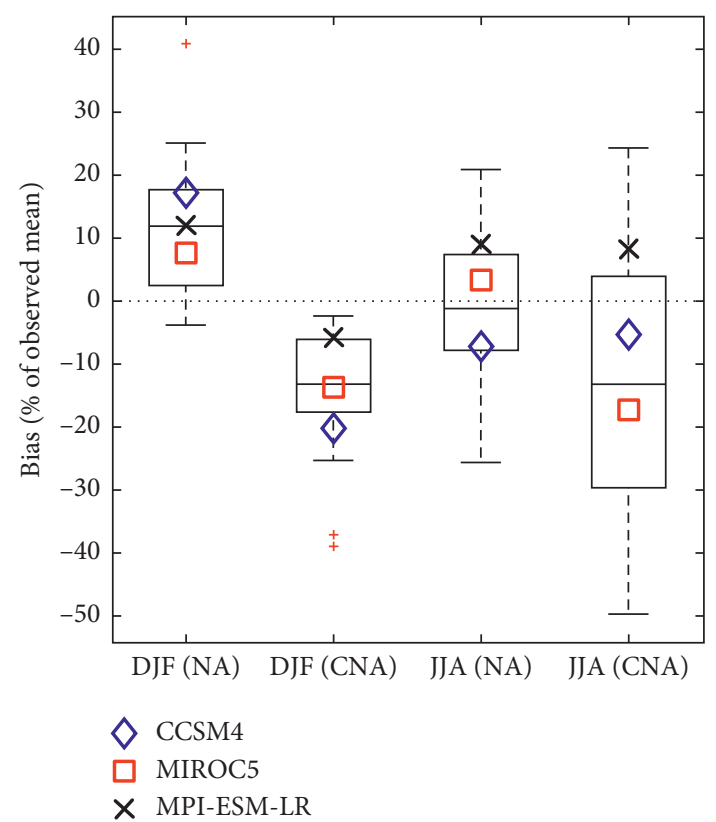

(a)

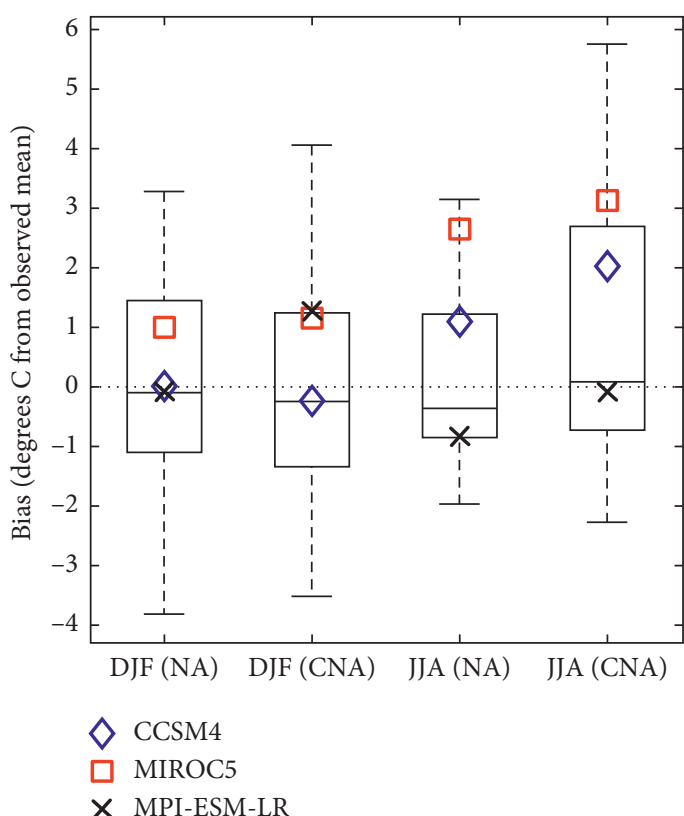

(b)

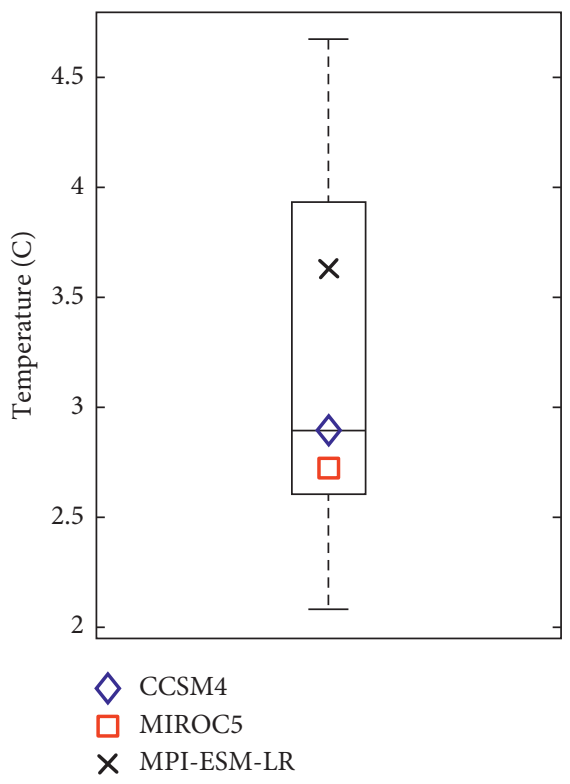

(c)

FIgURE 2: Performance assessment of the selected 3 GCMs (CCSM4, MIROC5, and MPI-ESM-LR) from the CMIP5 suite based on North American (NA) and central North American (CNA) winter (DJF) and summer (JJA) bias in (a) precipitation and (b) temperature, and (c) climate sensitivity (based on Sheffield et al. [30] and personal communication with Dr. Derek Rosendahl).

GCMs, we implemented quantile mapping techniques to downscale the output, also reducing biases in the large-scale climate models during postprocessing [32]. For example, all three chosen models have been shown to underestimate precipitation in the winter, and two of the models overestimate temperature in the summer for the central North America region [30]. In this case, quantile mapping helped to correct these biases in the probability distributions of the GCMs and were tested to find the sensitivity of the projections. Quantile mapping incudes a stationarity assumption, meaning that biases and patterns that occur in the historical period are assumed to also occur in the future period [33-36]. In addition, for precipitation downscaling, we used a threshold of $0.127 \mathrm{~mm}$ to classify rainfall days, while dry days were defined as those days with precipitation amounts falling below the threshold. This threshold is defined by the National Climatic Data Center [37].

\subsection{Cumulative Density Function Transform (CDFt) Method.} We selected the downscaling techniques of cumulative density function transform (CDFt) [38], equidistant quantile 
mapping (EDQM) [33, 39], and bias correction quantile mapping (BCQM) [40]. The CDFt downscaling technique uses a transfer function, shown in equation (1) [39], to identify the quantitative relationship between the modeled historical and the observed cumulative distribution functions and uses the same relationship to generate the future cumulative distribution function $(F)[41]$ :

$$
\widehat{x}_{\mathrm{m}, \mathrm{p}}(t)=F_{\mathrm{o}, \mathrm{h}}^{-1}\left(F_{\mathrm{m}, \mathrm{h}}\left(x_{\mathrm{m}, \mathrm{p}}\right)\right) \text {, }
$$

where subscripts represent observed (o), historical (h), modeled $(\mathrm{m})$, and predicted $(\mathrm{p})$ data; $x_{\mathrm{m}, \mathrm{p}}$ is the modeled climate variable that is being predicted; and $\bar{x}_{\mathrm{m}, \mathrm{p}}$ is the bias corrected climate variable. This equation improves the tail behavior of the projections by keeping the distribution within the bounds of the observed data, and the technique preserves the initial GCM means in the downscaled output by transforming the mean of the GCMs to match the historical observed means.

The two parameters used by CDFt are dev, the coefficient of development, which is the difference between the historical and future GCM mean and is used to extend the range for quantiles to be calculated, and npas, the number of quantiles that are being estimated. For this study, dev $=1$ and npas $=100$, the default. Pierce et al. [41] analyzed the CDFt method and their results revealed that this method generally produces lower precipitation estimates across the U.S. However, in the Red River Basin region, their findings indicated a wet bias across a large part of the region, especially during the summer. Daily maximum temperature was underestimated in their end-of-century projections for much of the basin in the summer as well.

3.4. Equidistant Quantile Mapping (EDQM) Method. The second method we used was EDQM and the downscaling was performed through the transfer functions in equations $(2)$ and $(3)[33,39]$. The modeled mean for the historical and predicted period is represented by $\bar{x}_{\mathrm{m}, \mathrm{h}}$ and $\bar{x}_{\mathrm{m}, \mathrm{p}}(t)$ [33]. A ratio approach (equation (2)) for EDQM versus an additive approach (equation (3)) for precipitation eliminates the possibility of negative precipitation values occurring after bias correction, which generally arises when a model has a wet bias and projects a decrease in precipitation [42]. Therefore, both methods were applied in the calculation of EDQM, with a ratio approach being implemented for precipitation and an additive approach for temperature.

$$
\begin{aligned}
& \widehat{x}_{\mathrm{m}, \mathrm{p}}(t)=F_{\mathrm{o}, \mathrm{h}}^{-1}\left\{F_{\mathrm{m}, \mathrm{h}}\left[\frac{\bar{x}_{\mathrm{m}, \mathrm{h}} x_{\mathrm{m}, \mathrm{p}}(t)}{\bar{x}_{\mathrm{m}, \mathrm{p}}(t)}\right]\right\} \frac{\bar{x}_{\mathrm{m}, \mathrm{p}}(t)}{\bar{x}_{\mathrm{m}, \mathrm{h}}}, \\
& \hat{x}_{\mathrm{m}, \mathrm{p}}(t)=x_{\mathrm{m}, \mathrm{p}}+F_{\mathrm{o}, \mathrm{h}}^{-1}\left(F_{\mathrm{m}, \mathrm{p}}\left(x_{\mathrm{m}, \mathrm{p}}\right)\right)-F_{\mathrm{m}, \mathrm{h}}^{-1}\left(F_{\mathrm{m}, \mathrm{p}}\left(x_{\mathrm{m}, \mathrm{p}}\right)\right) .
\end{aligned}
$$

EDQM assumes that the historical model error will persist in the future, and the technique bias corrects future temperature values by adding the historical bias value to the modeled change in that estimate at a given quantile across the grid points [41]. This method also upholds the modeled median change in the future. Pierce et al. [41] projected very wet and dry regions to have a higher error in precipitation; however, in the Red River Basin region, their estimates showed an underestimation of precipitation in the winter and an overestimation in summer. Temperature was relatively consistent between winter and summer, with a smaller mean error of -0.5 to 0.5 degrees Celsius.

Quantile mapping methods do not require a temporal structure, or sequence, that represents the historical record; however, the resulting downscaled projections are used for hydrologic impacts studies, applying the variable infiltration capacity model [43] for rainfall runoff and input to the RiverWare [12, 19] water management tool. Thus, it was essential to link the daily variability of the GCM and downscaled output from both techniques to create temporal consistency by creating an algorithm to reorganize the downscaled output to improve the correlation of the projections with the coarse-resolution GCM time-sequenced values. Once this process was complete, the downscaled data were quality controlled.

\subsection{Bias Correction Quantile Mapping (BCQM) Method.} It is worth noting that we intended to use the BCQM method [40] as a third downscaling technique; however, there were substantive issues found with our computations of this method. BCQM uses the transfer equation in equation (1), but it only includes historical observations for data training and disregards information from future projections [33]. This technique can alter the trends of the GCMs after bias correction substantially, which affects precipitation analyses and skews the data distribution [44]. The tail distribution becomes skewed when the model projects values that fall outside of the historical range used for training. When the variance is overestimated in the historical period, the mean and quantiles also are overestimated after bias correction and vice versa for underestimation [33]. Because of time constraints, we were unable to correct and rerun computations for this method and include it in our study. Therefore, the BCQM technique could not be recommended to decision makers in the Red River Basin and, therefore, was not used in our analyses, in impacts modeling, or for management decisions.

\section{Results}

The resulting ensemble of statistically downscaled climate projections for the Red River Basin was made publicly available in NetCDF format. The data include daily minimum and maximum temperatures (in degrees Kelvin) and daily precipitation (in $\mathrm{kg} / \mathrm{m}^{2} \mathrm{~s}$ ) from the described three GCMs and two downscaling techniques for the historical time period (1961-2005) and future period (2006-2099). There are 72 statistically downscaled projections created at a resolution of $0.1^{\circ}$, or approximately 11 kilometers latitude by 9 kilometers longitude, including 18 projections for the historical period and 54 projections for the future period. The gridded observational dataset [24] used as the downscaling training dataset is also available for validation purposes. 
Many analyses can be executed from these data. For example, in Section 4.1, we provide an analysis for the difference in mean daily values between the most recent 25 years in the historical period (1981-2005) and two 25-year segments of the future period (2046-2070 and 2075-2099) under RCP 2.6 and RCP 8.5 scenarios. We then computed the mean daily changes of precipitation for each season, which we discuss in Section 4.2. Detailed analyses of the dataset are available in Bertrand and McPherson [17].

4.1. Changes in Precipitation and Temperature. Our first example of an analysis that can be conducted from these data is a simple calculation of the projected changes in mean daily precipitation and daily minimum and maximum temperature between the historical and future time frames. We converted temperature to degrees Celsius and precipitation to millimeters per day. Overall, we determined that the models generally project an increasing precipitation trend in eastern portions of the Red River Basin and a decreasing trend in the west for both downscaling techniques, especially during the end-of-century period under RCP 8.5 (Figure 3). Under the CDFt technique, the CCSM4 and MPI-ESM-LR models estimate mean daily precipitation to decrease in the west up to $0.5 \mathrm{~mm} /$ day and increase in the east by up to $0.7 \mathrm{~mm} /$ day (Figure 3 ). In the historical period, $4-5 \mathrm{~mm}$ /day of mean daily precipitation occurred in the east, which indicates a $15 \%$ increase by the end of the $21^{\text {st }}$ century (Figure 4). In the west, historical mean daily precipitation ranged from $1-3 \mathrm{~mm} /$ day, which is a $15 \%$ decrease in the future.

The EDQM technique yielded a smaller range in precipitation differences, spanning from a $0.5-\mathrm{mm} /$ day decrease to a $0.4-\mathrm{mm} /$ day increase but exhibited the same spatial patterns as CDFt. On the other hand, the MIROC5 simulations demonstrated a basin-wide increase in precipitation for all RCPs and time frames with the exception of the endof-century scenario with RCP 8.5 , where a basin-wide decrease was projected from both downscaling techniques. Sillmann et al. [45] found that the MIROC5 model projects the highest precipitation totals among the CMIP5 models, which may explain the model's generally higher estimates. The differing results between models represent uncertainties in the models, downscaling methods, emission scenarios, and natural variability [46].

Projections for mean daily minimum temperature differed greatly between RCP 2.6 and RCP 8.5 scenarios. In a lower emission scenario, mean minimum daily temperatures increased up to $2^{\circ} \mathrm{C}$ for both time frames, while estimates in the higher emission scenario increased by as much as $6.6^{\circ} \mathrm{C}$ by the end of the century (Figures $5(\mathrm{a})-5(\mathrm{f})$ ) compared to the historical value of approximately $10^{\circ} \mathrm{C}$ (Figure 6). Mean daily maximum temperature is similar, and each projection revealed a basin-wide increase with no decreases in either minimum or maximum temperature (Figures $7(\mathrm{a})-7(\mathrm{f})$ ).

The largest warming was projected to occur in the endof-century time period of 2075-2099 under the RCP 8.5 scenario for all models and downscaling methods. However, MIROC5 exhibited warmer mean temperatures in the future time periods, with values being $1^{\circ} \mathrm{C}$ higher than the other two models. This difference can be explained by the warm bias in MIROC5 temperatures, as described in Sheffield et al. [30]. Sheffield also estimated a warm bias in MPI-ESM-LR for the central North America region. The CDFt and EDQM results were nearly equivalent in regard to temperature variables. Based on our results, precipitation and temperature seem to be more influenced by the GCM versus the downscaling technique, indicating more variability in the GCMs due to their own inherit biases and little variability in the downscaling technique. Nover et al. [47] describes this well, stating that locations driven by large-scale features are more affected by the GCM selection.

4.2. Seasonal Changes in Precipitation. To better understand the changes seen in Section 4.1, we computed the mean daily precipitation differences between the historical and future periods for each climatological season, categorized as December through February (DJF), March through May (MAM), June through August (JJA), and September through November (SON). Because modeled precipitation is more variable than temperature, we chose to only analyze the seasonal precipitation changes. Model projections indicated that the two downscaling techniques yielded similar results and spatial patterns.

In the mid-century period, the models generally projected a change of $0.5 \mathrm{~mm} /$ day from the historical value; however, there were distinct patterns in some models. For example, the CCSM4 model exhibited the largest changes in mean daily precipitation. This model estimated the mean daily precipitation to increase by $2 \mathrm{~mm} /$ day in the MAM time frame, compared to less than $0.5 \mathrm{~mm} /$ day in the other models (Figure 8). This substantial amount revealed a $40 \%$ increase compared to historical values. Furthermore, the model projected a basin-wide decrease in the JJA time frame with some locations having a reduction of $0.85 \mathrm{~mm} /$ day, while the other two models included a large-scale increase in mean daily precipitation. This result shows that the CCSM4 model projects more extreme values during the spring and balances its annual average by a widespread reduction during the summer in the mid-century period. Qiao et al. [48] analyzed seasonal precipitation in the Red River Basin and used the same dataset as our study for the mid-century time frame. Their results showed that the highest increases in precipitation occur in the spring and largest decreases were in the fall for the mid-century period. In addition, they discovered that precipitation amounts in the upper quantiles are driving the precipitation totals in spring, which may validate that CCSM4 projects more extreme events in spring. Their results are consistent with ours.

On the other hand, larger changes were seen in the endof-century period under RCP 8.5. We noticed the same previous patterns for the CCSM4 model, but the largest changes emerged in the MPI-ESM-LR model (Figure 9). For example, mean daily precipitation in the DJF period increased by $1.68 \mathrm{~mm}$ in the eastern basin, which is more than $30 \%$ greater than the historical value. Precipitation increased 


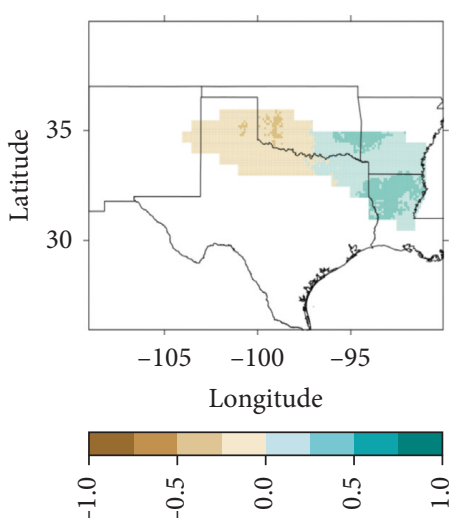

(a)

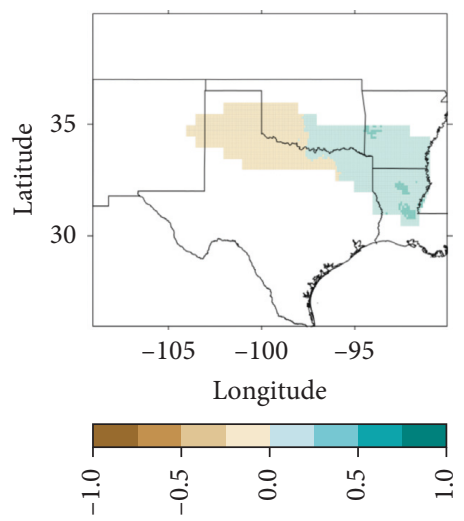

(d)

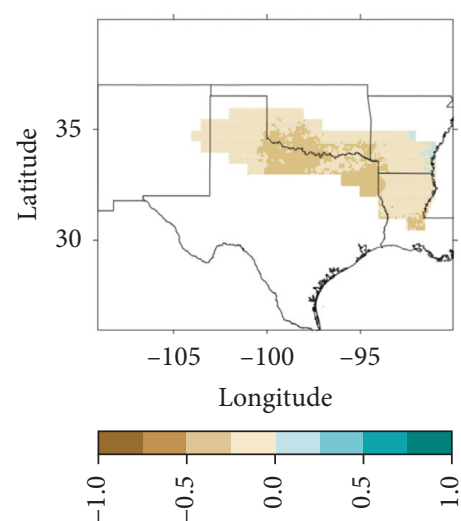

(b)

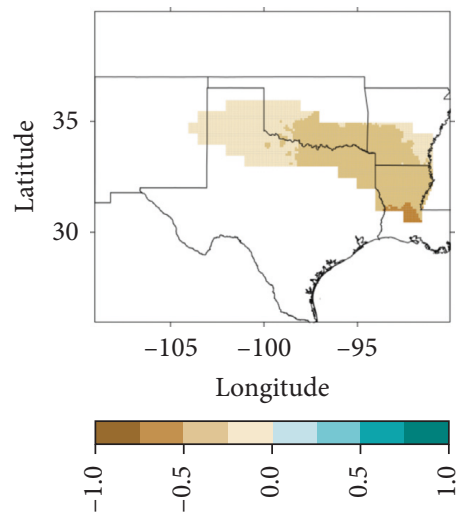

(e)

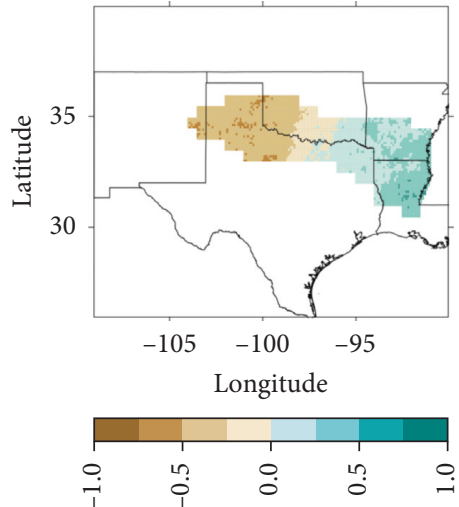

(c)

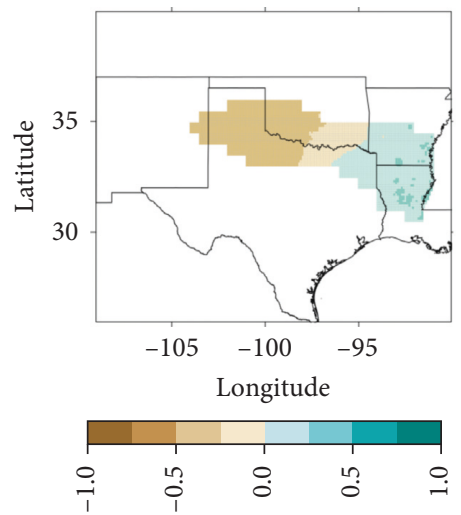

(f)

Figure 3: Difference fields for mean daily precipitation (in mm/day) between historical (1981-2005) and end-of-century (2075-2099) time frames for RCP 8.5. Columns represent the GCMs (CCSM4, MIROC5, and MPI-ESM-LR, from left to right respectively); rows represent downscaling methods, with CDFt on top and EDQM on bottom. Brown and tan colors represent future decreases in precipitation compared to the historical period; blue-green colors represent future increases in precipitation. (a) Model: CCSM4, SD: CDFt. (b) Model: MIROC5, SD: CDFt. (c) Model: MPI-ESM-LR, SD: CDFt. (d) Model: CCSM4, SD: EDQM. (e) Model: MIROC5, SD: EDQM. (f) Model: MPI-ESM-LR, SD: EDQM.

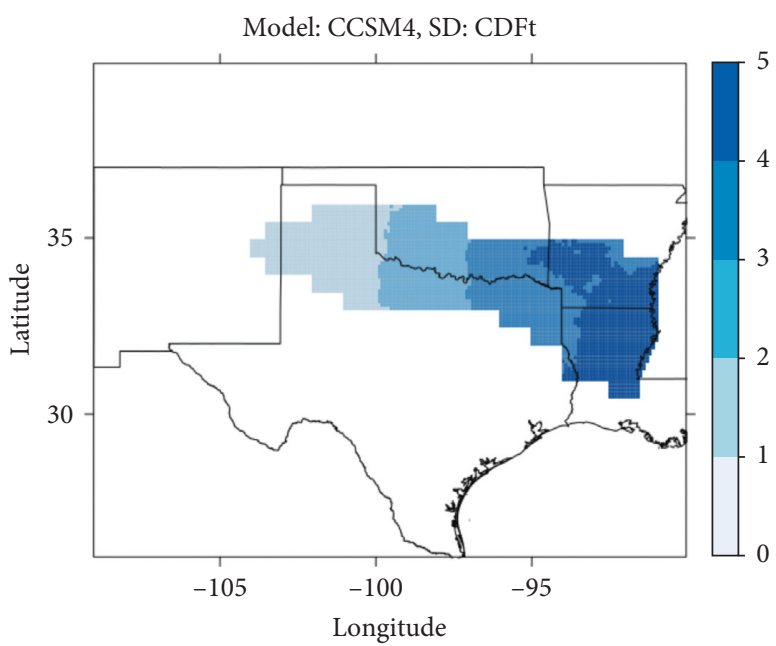

FIgURE 4: Difference fields for the CCSM4 mean daily precipitation (in $\mathrm{mm} /$ day) for the historical (1981-2005) time frame. Darker shades of blue represent higher rainfall values.

in the JJA period as well, along with a decrease of $1.3 \mathrm{~mm} /$ day in the Texas Panhandle. Furthermore, this model projected the largest MAM decreases. Meanwhile, the MIROC5 model included small changes throughout most of the year. Precipitation uncertainties are evident by the end of the $21^{\text {st }}$ century and two of the three models show that extreme values are likely driving the seasonal trends.

\section{Discussion about Climate Risk Assessment}

Although it is important to document the methods that created the ensemble of climate projections for this case study in the Red River Basin, much of what was learned from the process of generating the dataset involved coproduction of knowledge with impacts modelers (in this case, for streamflow and channel routing) and decision makers (in this case, water resource managers). First, impacts modelers and decision makers both must rely on climate scientists to value their management outcomes in order to produce useable climate projections. In Section 3.5, we noted that all variables for all scenarios, GCMs, and time periods were generated using the BCQM downscaling technique; however, instabilities in the resulting output led the climate scientists to remove that dataset from further processing and analyses for their coproduction partners. Without the expertise of the climate scientists, it is probable (perhaps even 


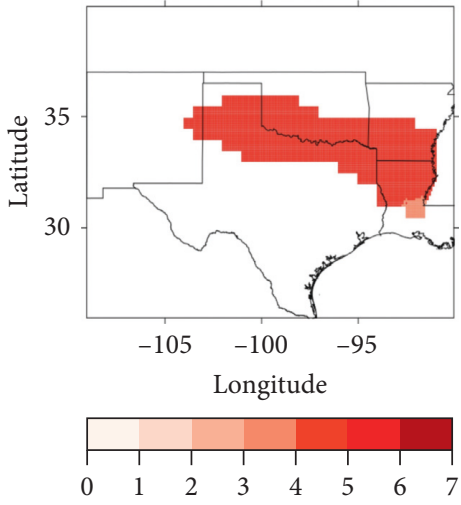

(a)

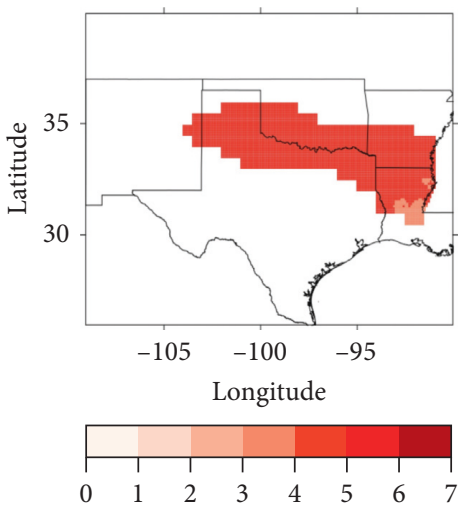

(d)

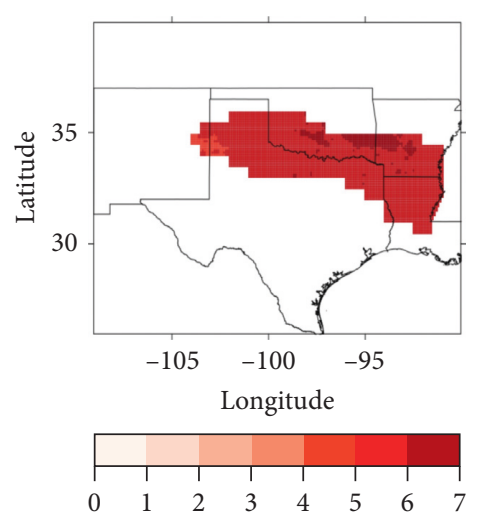

(b)

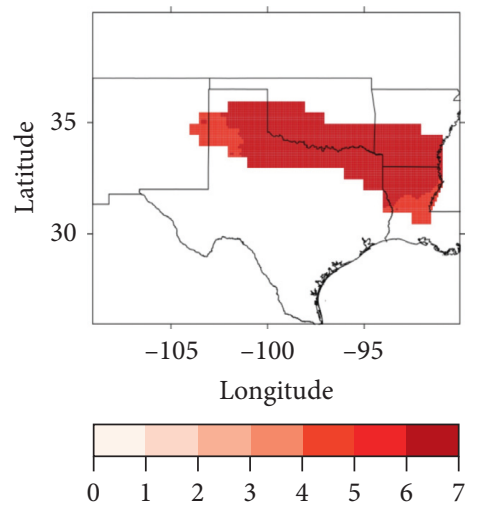

(e)

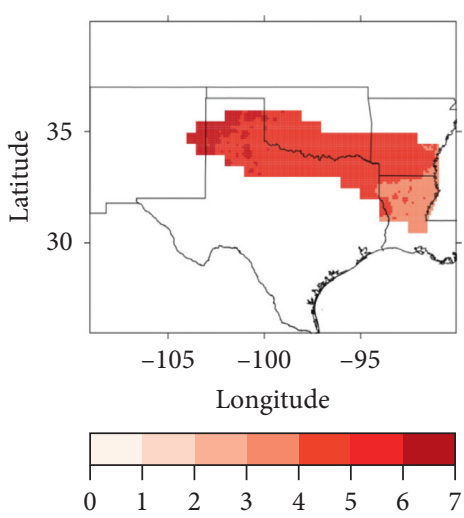

(c)

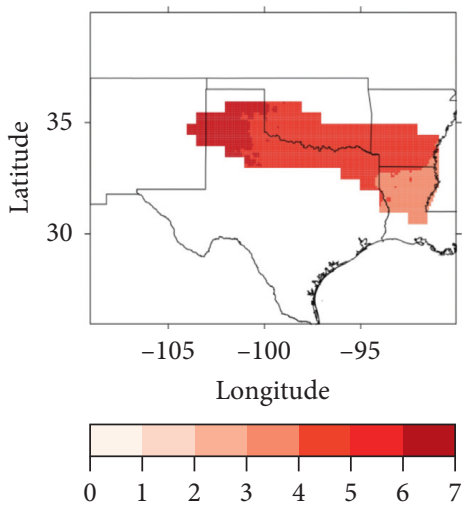

(f)

Figure 5: Difference fields for mean daily minimum temperature $\left({ }^{\circ} \mathrm{C}\right)$ between historical (1981-2005) and end-of-century (2075-2099) time frames for RCP 8.5. Columns represent the GCMs (CCSM4, MIROC5, and MPI-ESM-LR, from left to right respectively); rows represent downscaling methods, with CDFt on top and EDQM on bottom. Darker shades of red represent higher minimum temperature values. (a) Model: CCSM4, SD: CDFt. (b) Model: MIROC5, SD: CDFt. (c) Model: MPI-ESM-LR, SD: CDFt. (d) Model: CCSM4, SD: EDQM. (e) Model: MIROC5, SD: EDQM. (f) Model: MPI-ESM-LR, SD: EDQM.

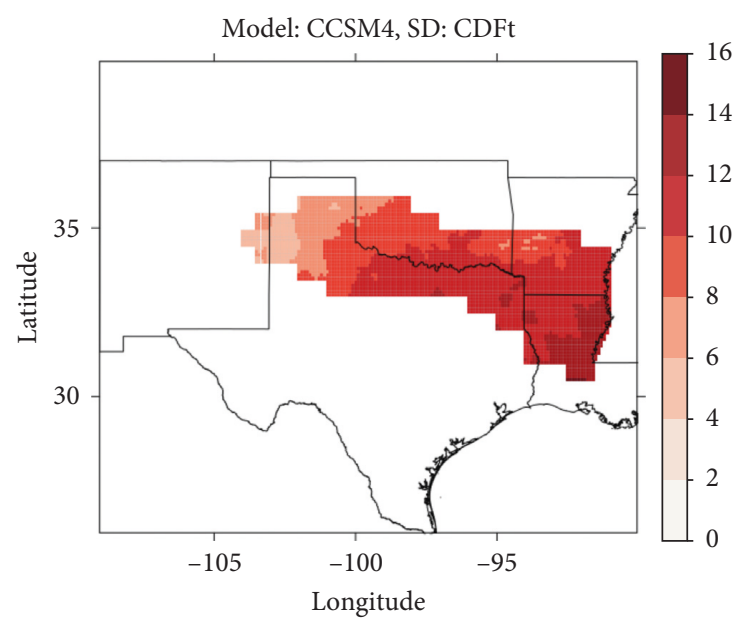

Figure 6: Difference fields for mean daily minimum temperature $\left({ }^{\circ} \mathrm{C}\right)$ for the historical (1981-2005) time frame for CCSM4. Dark shades of red represent higher minimum temperature values.

likely) that impacts modelers or water resource managers would have included these anomalous results in their work.

Similarly, in Section 3.4, we discussed how we implemented a ratio approach for precipitation and an additive approach for temperature in the calculation of the EDQM datasets. This choice is one of many that can be applied during the creation of a downscaled dataset, and each of these choices can affect the resulting output (e.g., Wootten 


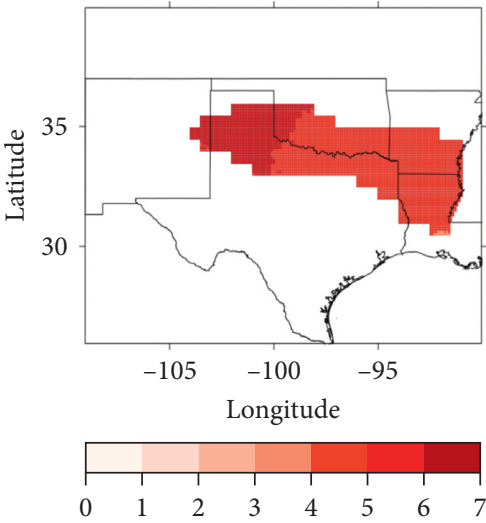

(a)

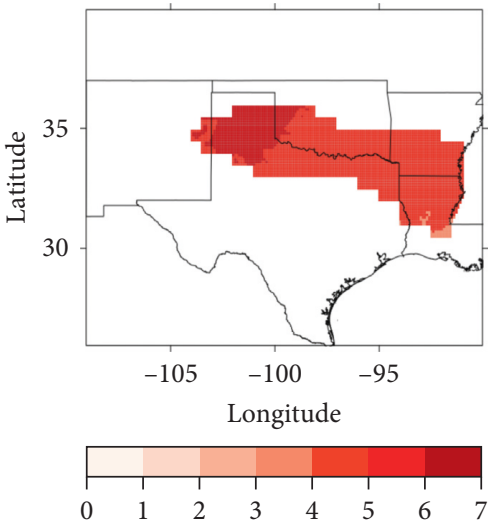

(d)

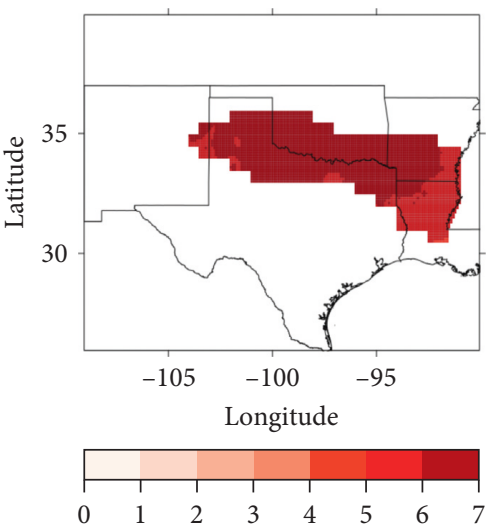

(b)

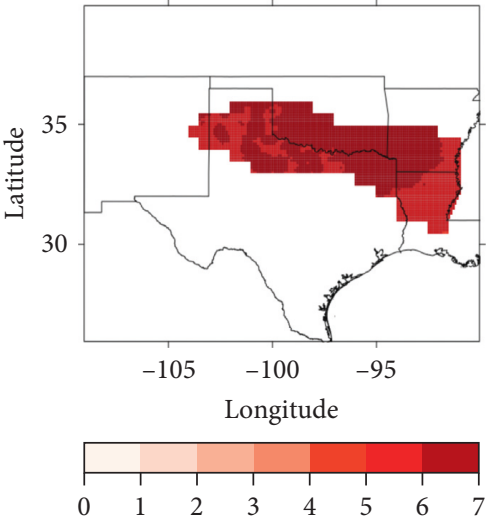

(e)

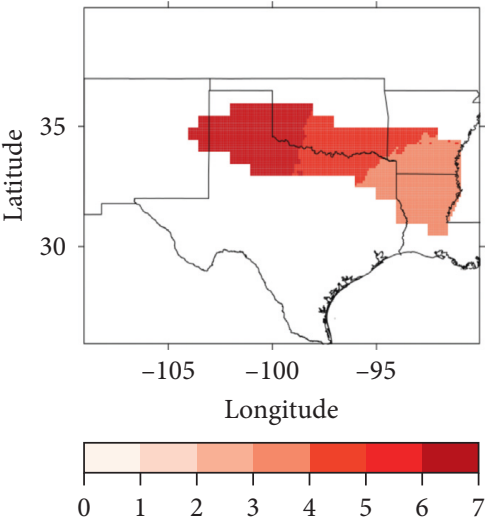

(c)

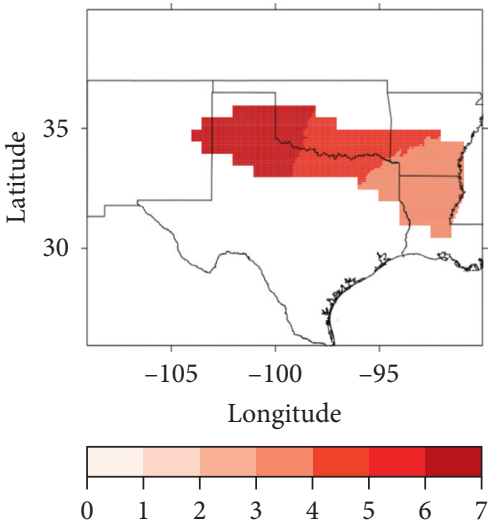

(f)

Figure 7: Difference fields for mean daily maximum temperature $\left({ }^{\circ} \mathrm{C}\right)$ between historical (1981-2005) and end-of-century (2075-2099) time frames for RCP 8.5. Columns represent the GCMs (CCSM4, MIROC5, and MPI-ESM-LR, from left to right respectively); rows represent downscaling methods, with CDFt on top and EDQM on bottom. Darker shades of red represent higher maximum temperature values. (a) Model: CCSM4, SD: CDFt. (b) Model: MIROC5, SD: CDFt. (c) Model: MPI-ESM-LR, SD: CDFt. (d) Model: CCSM4, SD: EDQM. (e) Model: MIROC5, SD: EDQM. (f) Model: MPI-ESM-LR, SD: EDQM.

[29]), especially for extreme values and longer projections. Other choices include data transformations (e.g., to transform non-Gaussian distributions like precipitation for application to statistical techniques that assume Gaussian distributions), regridding or interpolating GCM output to the same spatial and temporal resolution of the gridded observational dataset used in training the statistical technique and implementing a tail adjustment (for extreme values) within the downscaling process. Again, because these choices affect the resulting downscaled projections, users of the projections need to work closely with climate scientists to understand how these choices may affect their own decisions.

On the other hand, value is added to the development of downscaled datasets through coproduction with impacts modelers and decision makers in the field. In this case study, we teamed with hydrologists at the University of Oklahoma and Aqua Strategies Inc., a private water resources consulting firm, to use the output of our downscaling processes as input to the variable infiltration capacity (VIC) model $[43,49]$, which is a physically based, semidistributed water and energy balance model that outputs surface hydrological variables, including streamflow. Xue et al. [19] detail results from the VIC model using downscaled input for this Red River case study. Many other river basin studies have used the VIC model for climate change impact assessments as well $[50,51]$. Hydrologic projections from the VIC model then were used as input to RiverWare ${ }^{\mathrm{TM}}$ [52], developed by the Center for Advanced Decision Support for Water and Environmental Systems (CADSWES), to model the river/reservoir system of the Red River Basin. RiverWare is used extensively for water planning because it allows users to simulate management operations across a complex basin, including various types of reservoirs, canals, diversions, and users. Water managers from the Chickasaw Nation and Choctaw Nation of Oklahoma ultimately were users of the resulting information as they worked on a 50-year water plan. Conversations between the climate scientists, hydrologic modelers, and water managers resulted in many of the choices discussed above in the downscaling development. When climate scientists understood the kinds of decisions that were being made, it became apparent when a given set of output would be unhelpful or even harmful to the risk assessment process. Given the project timeline, it was 

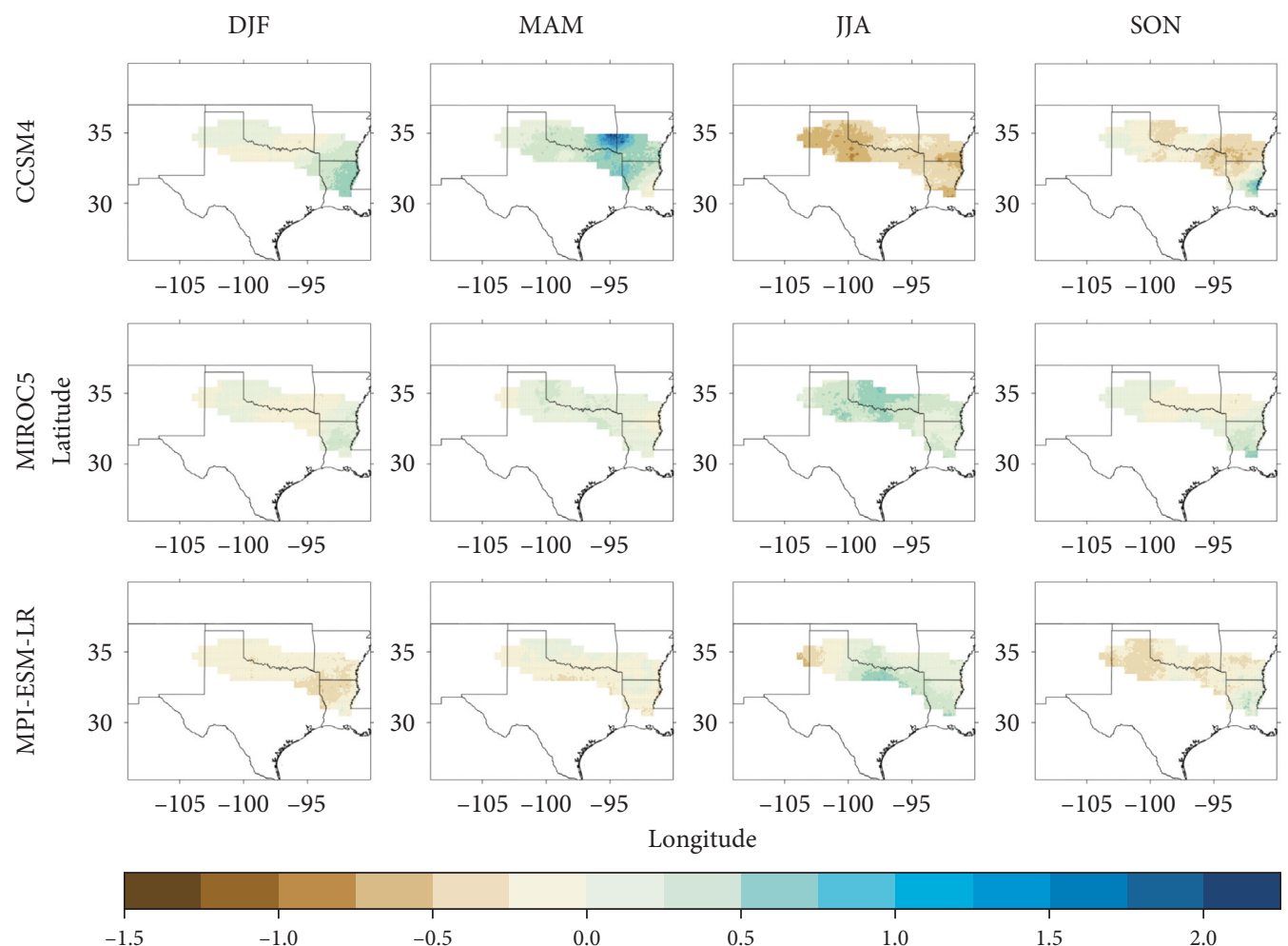

(a)
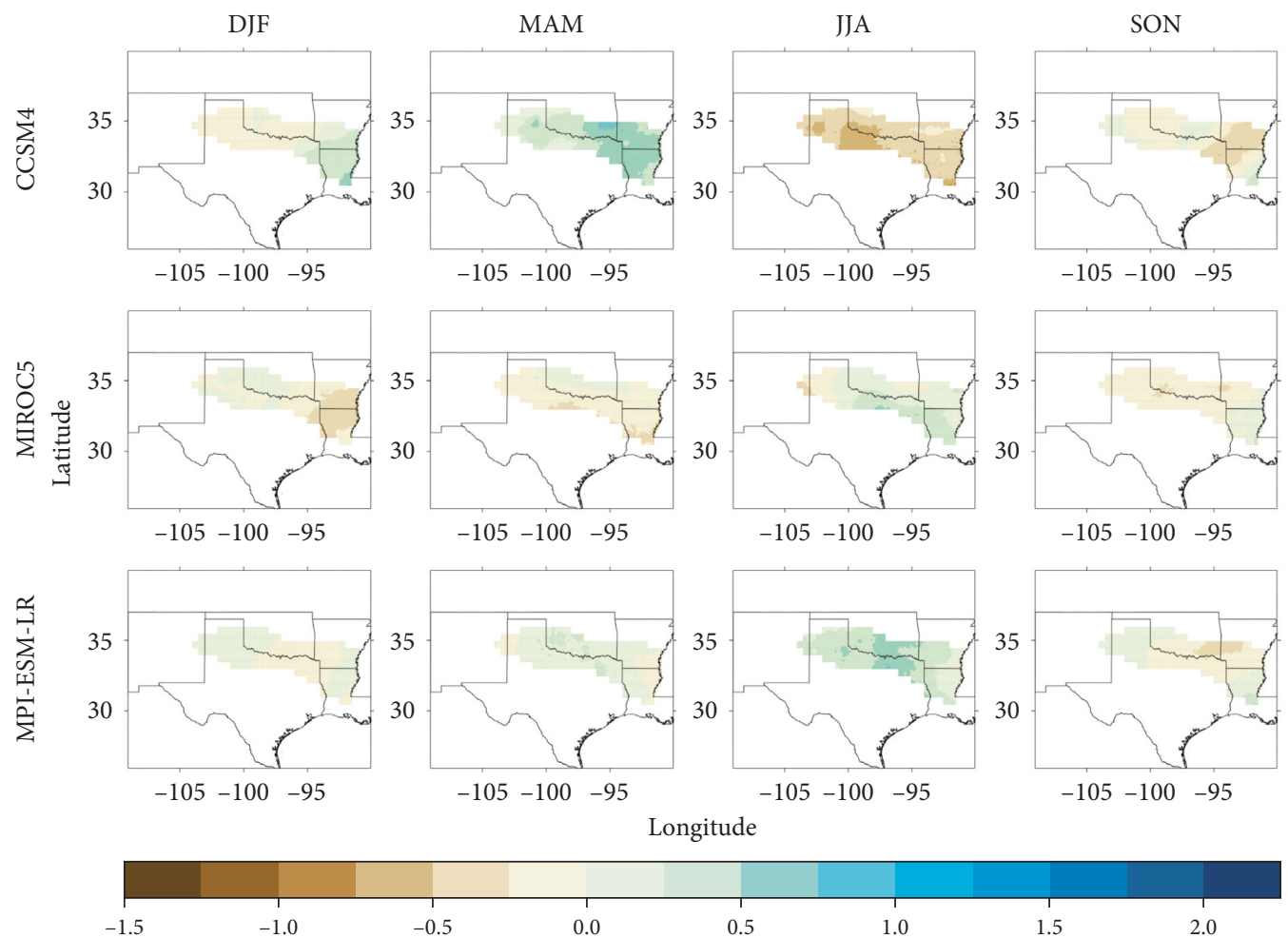

(b)

FiguRE 8: Difference field in seasonal changes in mean daily precipitation (mm/day) between the historical (1981-2005) and mid-century (2046-2070) time frames for RCP 2.6 using the (a) CDFt downscaling technique and (b) EDQM technique. Columns represent seasons (DJF, MAM, JJA, and SON). Brown colors represent a decrease in daily precipitation and blues represent an increase. 

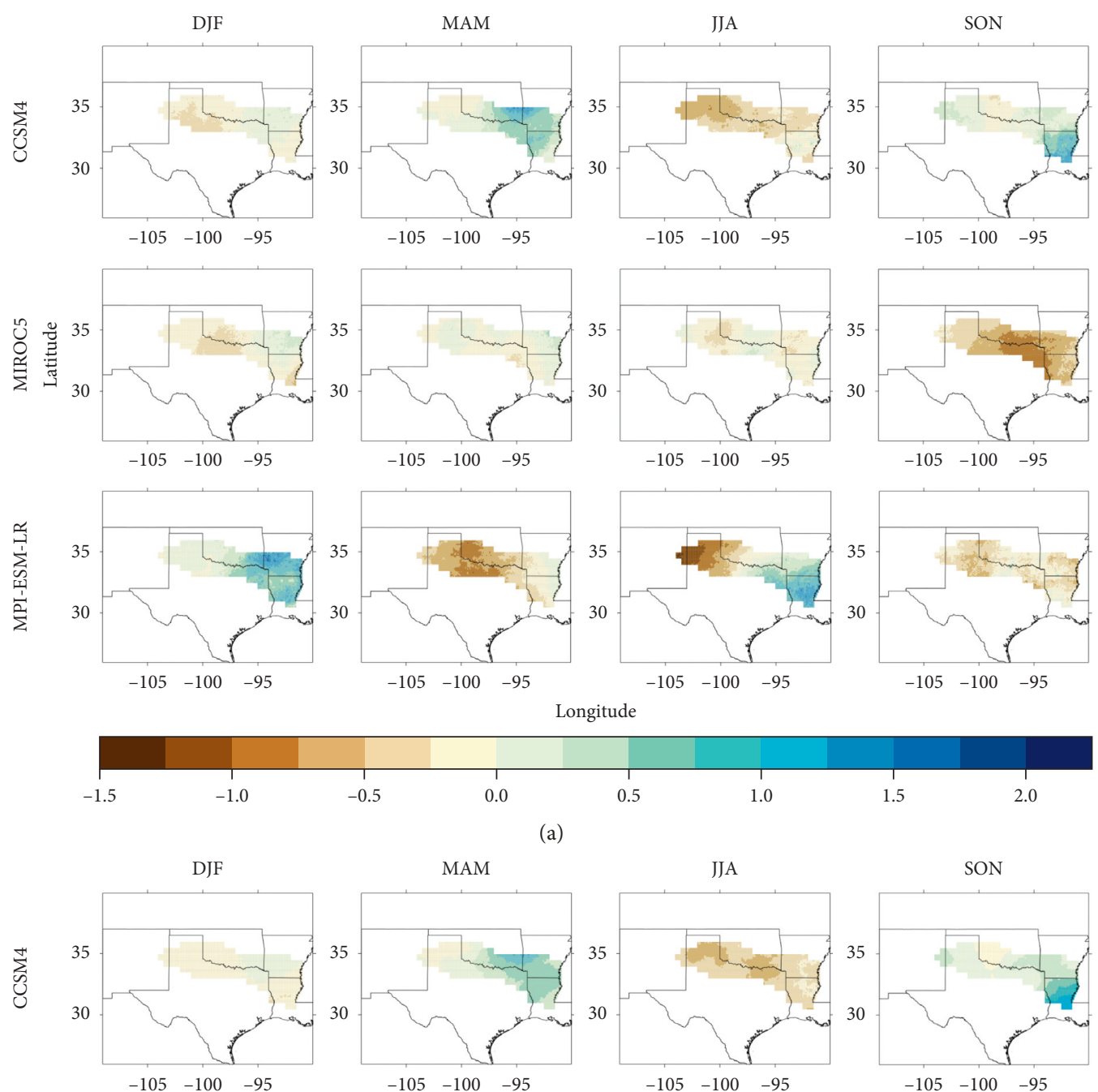

(a)
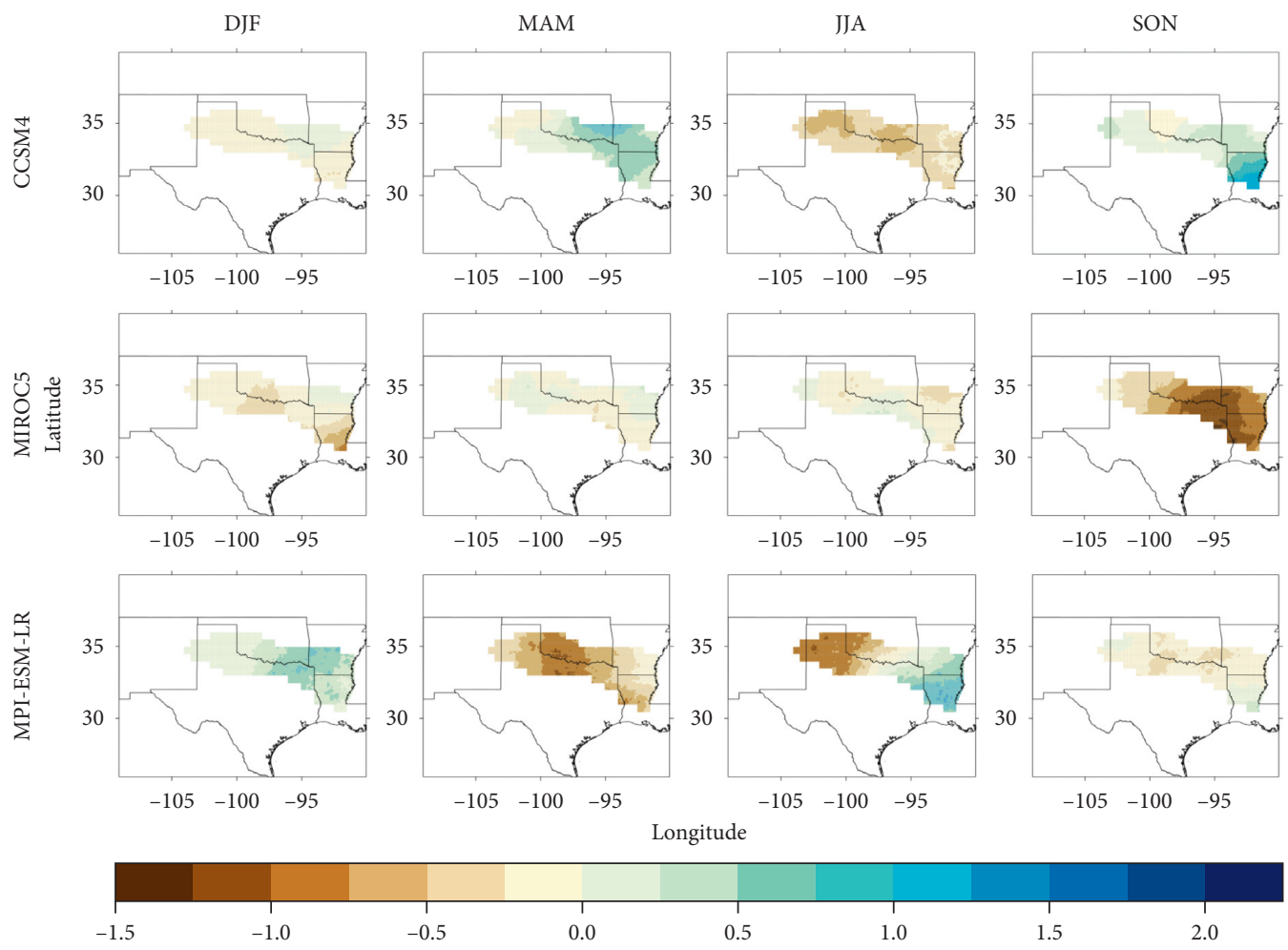

(b)

Figure 9: Difference fields in seasonal changes in mean daily precipitation (mm/day) between the historical (1981-2005) and end-of-century (2075-2099) time frames for RCP 8.5 using the (a) CDFt downscaling technique and (b) EDQM technique. Columns represent seasons (DJF, MAM, JJA, and SON). Brown colors represent a decrease in daily precipitation and blues represent an increase. 
impossible to apply a different downscaling technique, for example, when BCQM resulted in spurious output for some cases, but at least the communications among the three groups could result in the nations not using problematic climate projections for their planning process.

\section{Conclusions}

Statistically downscaled climate projections provide highresolution output that is more useful to water managers, decision makers, and researchers than coarse-resolution global climate models. This study introduced datasets that include downscaling from three GCMs (CCSM4, MPI-ESMLR, and MIROC5) using two statistical downscaling techniques (CDFt and EDQM) at a resolution of $0.1^{\circ}$ for the Red River Basin. The datasets contain a historical time period (1961-2005) and a future period (2006-2099) and project daily minimum and maximum temperature and daily precipitation through the end of the $21^{\text {st }}$ century. Value was ultimately added to these datasets through coproduction of knowledge with impacts modelers and decision makers, which created usable climate projections for the end users' climate risk assessments. By working with these groups, we were able to identify their needs and make the appropriate decisions for the downscaling development.

While there are uncertainties in the models, downscaling techniques, and future emissions, results of the mean daily differences between historical and future climate variables indicate a decrease in mean daily precipitation in western portions of the basin and an increase in the east by the end of the century. Our seasonal analysis indicates that extreme values in some seasons may be driving the trends in mean daily precipitation, especially in the end-of-century period under RCP 8.5. In addition, daily minimum and maximum temperatures were projected to increase across the basin by up to $7^{\circ} \mathrm{C}$, especially toward the end of the century and under a higher emission scenario. Results suggest that water resource managers and decision makers should not focus on one model or one downscaling technique, but the general trends show that they may need to plan for drier and hotter conditions in the western Red River Basin and wetter and hotter conditions in the east. Our analysis explores one possibility of the use of these datasets; however, it can be beneficial for many other studies regarding climatological and hydrological aspects in the region. Coproduction of knowledge between climate scientists and end users leads to data that are usable for those making decisions and climate risk assessments.

\section{Data Availability}

The NetCDF data used to support the findings of this study have been deposited in the Downscaling-Red River Basin repository (statistically downscaled time series for the Red River Basin (South Central U.S.A.), DOI: 10.15763/DBS.SCCSC.RR; (a) 1/ $10^{\text {th }}$ of a degree observation based dataset, DOI: $10.15763 /$ DBS.SCCSC.RR.0001; (b) downscaled climate variables from the CCSM4 GCM, DOI: 10.15763/DBS.SCCSC.RR.0002; (c) downscaled climate variables from the MIROC5 GCM, DOI:
10.15763/DBS.SCCSC.RR.0003; (d) downscaled climate variables from the MPI-ESM-LR GCM, DOI: 10.15763/ DBS.SCCSC.RR.0004).

\section{Conflicts of Interest}

The authors declare that there are no conflicts of interest regarding the publication of this paper.

\section{Acknowledgments}

This material is based on the work supported by The National Science Foundation (Grant number OIA-1301789). In addition, support was provided by the Oklahoma Established Program to Stimulate Competitive Research (EPSCoR), the South Central Climate Adaptation Science Center, and the Southern Climate Impacts Planning Program. The authors give thanks to Keith, John L., Carlos, and others at GFDL for developing the datasets and thanks to impacts modelers at the University of Oklahoma and Aqua Strategies and water managers at Chickasaw Nation and Choctaw Nation of Oklahoma for working with us on the project.

\section{References}

[1] E. P. Maurer, L. Brekke, T. Pruitt et al., "An enhanced archive facilitating climate impacts and adaptation analysis," Bulletin of the American Meteorological Society, vol. 95, no. 7, pp. 1011-1019, 2014.

[2] B. Thrasher, J. Xiong, W. Wang, F. Melton, A. Michaelis, and R. Nemani, "Downscaled climate projections suitable for resource management," Eos, Transactions American Geophysical Union, vol. 94, no. 37, pp. 321-323, 2013.

[3] A. W. Wood, L. R. Leung, V. Sridhar, and D. P. Lettenmaier, "Hydrologic implications of dynamical and statistical approaches to downscaling climate model outputs," Climatic Change, vol. 62, no. 1-3, pp. 189-216, 2004.

[4] IPCC, "What is a GCM?," 2013, http://www.ipcc-data.org/ guidelines/pages/gcm_guide.html.

[5] R. H. Moss, J. A. Edmonds, K. A. Hibbard et al., "The next generation of scenarios for climate change research and assessment," Nature, vol. 463, no. 7282, pp. 747-756, 2010.

[6] F. Feser, B. Rockel, H. von Storch, J. Winterfeldt, and M. Zahn, "Regional climate models add value to global model data: a review and selected examples," Bulletin of the American Meteorological Society, vol. 92, no. 9, pp. 1181-1192, 2011.

[7] C. Prudhomme, N. Reynard, and S. Crooks, "Downscaling of global climate models for flood frequency analysis: where are we now?," Hydrological Processes, vol. 16, no. 6, pp. 11371150, 2002.

[8] M. A. Semenov and E. M. Barrow, "Use of a stochastic weather generator in the development of climate change scenarios," Climatic Change, vol. 35, no. 4, pp. 397-414, 1997.

[9] UCAR, "Climate modeling," 2011, http://scied.ucar.edu/ longcontent/climate-modeling.

[10] J. M. Eden, M. Widmann, D. Grawe, and S. Rast, "Skill, correction, and downscaling of GCM-simulated precipitation," Journal of Climate, vol. 25, no. 11, pp. 3970-3984, 2012.

[11] J. Schmidli, C. Frei, and P. L. Vidale, "Downscaling from GCM precipitation: a benchmark for dynamical and statistical downscaling methods," International Journal of Climatology, vol. 26, no. 5, pp. 679-689, 2006. 
[12] E. A. Zagona, T. J. Fulp, R. Shane, T. Magee, and H. M. Goranflo, "Riverware: a generalized tool for complex reservoir system modeling1," JAWRA Journal of the American Water Resources Association, vol. 37, no. 4, pp. 913-929, 2001.

[13] R. L. Wilby, S. P. Charles, E. Zorita, B. Timbal, P. Whetton, and L. O. Mearns, "Guidelines for use of climate scenarios developed from statistical downscaling methods. Intergovernmental panel on climate change (IPCC) task group on data and scenario support for impacts and climate analysis (TGICA)," 2004, http://ipcc-ddc.cru.uea.ac.uk/guidelines/ StatDown_Guide.pdf.

[14] K. Venkataraman, S. Tummuri, A. Medina, and J. Perry, "21st century drought outlook for major climate divisions of Texas based on CMIP5 multimodel ensemble: implications for water resource management," Journal of Hydrology, vol. 534, pp. 300-316, 2016.

[15] Q. Zhang and J. Zhang, "Drought hazard assessment in typical corn cultivated areas of China at present and potential climate change," Natural Hazards, vol. 81, no. 2, pp. 1323-1331, 2016.

[16] W.-H. Nam, M. J. Hayes, M. D. Svoboda, T. Tadesse, and D. A. Wilhite, "Drought hazard assessment in the context of climate change for South Korea," Agricultural Water Management, vol. 160, pp. 106-117, 2015.

[17] D. Bertrand and R. A. McPherson, "Future hydrologic extremes of the Red River basin," Journal of Applied Meteorology and Climatology, vol. 57, no. 6, pp. 1321-1336, 2018.

[18] U.S. Environmental Protection Agency, "Level III ecoregions of the continental United States," 2013, ftp://newftp.epa.gov/ EPADataCommons/ORD/Ecoregions/us/Eco_Level_III_US. pdf.

[19] X. Xue, K. Zhang, Y. Hong et al., "New multisite cascading calibration approach for hydrological models: case study in the Red River basin using the VIC model," Journal of Hydrologic Engineering, vol. 21, no. 2, Article ID 05015019, 2015.

[20] Oklahoma Water Resources Board, "Red River Compact Commission,” 2016, https://www.owrb.ok.gov/rrccommission/ rrccommission.html.

[21] J. Malewitz, "Red river showdown: Texas-Oklahoma water war could reverberate across US," McClatchy-Tribune Business News, Tribune Content Agency LLC, 2013.

[22] Tarrant Regional Water District versus Herrmann, 569 U. S. (2013).

[23] F. Giorgi, B. Hewitson, J. Christensen, M. Hulme, and H. von Storch, "Regional climate information-evaluation and projections," in Climate Change 2001: The Scientific Bases, Cambridge University Press, Cambridge, UK, 2001.

[24] B. Livneh, E. A. Rosenberg, C. Lin et al., "A long-term hydrologically based dataset of land surface fluxes and states for the conterminous United States: update and extensions," Journal of Climate, vol. 26, no. 23, pp. 9384-9392, 2013.

[25] K. E. Taylor, R. J. Stouffer, and G. A. Meehl, "An overview of CMIP5 and the experiment design," Bulletin of the American Meteorological Society, vol. 93, no. 4, pp. 485-498, 2012.

[26] M. A. Giorgetta, J. Jungclaus, C. H. Reick et al., "Climate and carbon cycle changes from 1850 to 2100 in MPI-ESM simulations for the Coupled Model Intercomparison Project phase 5," Journal of Advances in Modeling Earth Systems, vol. 5, no. 3, pp. 572-597, 2013.

[27] P. R. Gent, G. Danabasoglu, L. J. Donner et al., "The community climate system model version 4," Journal of Climate, vol. 24, no. 19, pp. 4973-4991, 2011.

[28] M. Watanabe, T. Suzuki, R. O'ishi et al., "Improved climate simulation by MIROC5: mean states, variability, and climate sensitivity," Journal of Climate, vol. 23, no. 23, pp. 6312-6335, 2010.

[29] A. Wootten, "The subtle processes in statistical downscaling and the potential uncertainty," US Clivar Variations, vol. 16, no. 3, pp. 8-13, 2018, https://usclivar.org/newsletter/newsletters.

[30] J. Sheffield, A. P. Barrett, B. Colle et al., "North American climate in CMIP5 experiments. Part I: evaluation of historical simulations of continental and regional climatology," Journal of Climate, vol. 26, no. 23, pp. 9209-9245, 2013.

[31] P. M. Forster, T. Andrews, P. Good, J. M. Gregory, L. S. Jackson, and M. Zelinka, "Evaluating adjusted forcing and model spread for historical and future scenarios in the CMIP5 generation of climate models," Journal of Geophysical Research: Atmospheres, vol. 118, no. 3, pp. 1139-1150, 2013.

[32] M. J. Themeßl, A. Gobiet, and A. Leuprecht, "Empiricalstatistical downscaling and error correction of daily precipitation from regional climate models," International Journal of Climatology, vol. 31, no. 10, pp. 1530-1544, 2011.

[33] A. J. Cannon, S. R. Sobie, and T. Q. Murdock, "Bias correction of GCM precipitation by quantile mapping: how well do methods preserve changes in quantiles and extremes?," Journal of Climate, vol. 28, no. 17, pp. 6938-6959, 2015.

[34] K. W. Dixon, J. R. Lanzante, M. J. Nath et al., "Evaluating the stationarity assumption in statistically downscaled climate projections: is past performance an indicator of future results?," Climatic Change, vol. 135, no. 3-4, pp. 395-408, 2016.

[35] D. Maraun, "Nonstationarities of regional climate model biases in European seasonal mean temperature and precipitation sums," Geophysical Research Letters, vol. 39, no. 6, Article ID L06706, 2012.

[36] P. C. D. Milly, J. Betancourt, M. Falkenmark et al., "Stationarity is dead: whither water management?," Science, vol. 319, no. 5863, pp. 573-574, 2008.

[37] National Climatic Data Center, Surface Land Daily Cooperative Summary of the Day. NCDC Data Documentation for Data Set 3200, National Climatic Data Center, Asheville, NC, USA, 2009.

[38] P. A. Michelangeli, M. Vrac, and H. Loukos, "Probabilistic downscaling approaches: application to wind cumulative distribution functions," Geophysical Research Letters, vol. 36, no. 11, Article ID L11708, 2009.

[39] H. Li, J. Sheffield, and E. F. Wood, "Bias correction of monthly precipitation and temperature fields from intergovernmental panel on climate change AR4 models using equidistant quantile matching," Journal of Geophysical Research: Atmospheres, vol. 115, no. D10, Article ID D10101, 2010.

[40] C. K. Ho, D. B. Stephenson, M. Collins, C. A. T. Ferro, and S. J. Brown, "Calibration strategies: a source of additional uncertainty in climate change projections," Bulletin of the American Meteorological Society, vol. 93, no. 1, pp. 21-26, 2012.

[41] D. W. Pierce, D. R. Cayan, E. P. Maurer, J. T. Abatzoglou, and K. C. Hegewisch, "Improved bias correction techniques for hydrological simulations of climate change," Journal of $\mathrm{Hy}$ drometeorology, vol. 16, no. 6, pp. 2421-2442, 2015.

[42] L. Wang and W. Chen, "Equiratio cumulative distribution function matching as an improvement to the equidistant approach in bias correction of precipitation," Atmospheric Science Letters, vol. 15, no. 1, pp. 1-6, 2014.

[43] X. Liang, E. F. Wood, and D. P. Lettenmaier, "Surface soil moisture parameterization of the VIC-2L model: evaluation and modification," Global and Planetary Change, vol. 13, no. 1-4, pp. 195-206, 1996. 
[44] E. P. Maurer and D. W. Pierce, "Bias correction can modify climate model simulated precipitation changes without adverse effect on the ensemble mean," Hydrology and Earth System Sciences, vol. 18, no. 3, pp. 915-925, 2014.

[45] J. Sillmann, V. V. Kharin, X. Zhang, F. W. Zwiers, and D. Bronaugh, "Climate extremes indices in the CMIP5 multimodel ensemble: Part 1. Model evaluation in the present climate," Journal of Geophysical Research: Atmospheres, vol. 118, no. 4, pp. 1716-1733, 2013.

[46] R. Knutti and J. Sedláček, "Robustness and uncertainties in the new CMIP5 climate model projections," Nature Climate Change, vol. 3, no. 4, pp. 369-373, 2013.

[47] D. M. Nover, J. W. Witt, J. B. Butcher, T. E. Johnson, and C. P. Weaver, "The effects of downscaling method on the variability of simulated watershed response to climate change in five U.S. basins," Earth Interactions, vol. 20, no. 11, pp. 1-27, 2016.

[48] L. Qiao, C. B. Zou, C. F. Gaitán, Y. Hong, and R. A. McPherson, "Analysis of precipitation projections over the climate gradient of the Arkansas Red River basin," Journal of Applied Meteorology and Climatology, vol. 56, no. 5, pp. 1325-1336, 2017.

[49] X. Liang, D. P. Lettenmaier, E. F. Wood, and S. J. Burges, “A simple hydrologically based model of land surface water and energy fluxes for general circulation models," Journal of Geophysical Research, vol. 99, no. D7, pp. 14415-14428, 1994.

[50] N. Nyaupane, B. Thakur, A. Kalra, and S. Ahmad, "Evaluating future flood scenarios using CMIP5 climate projections," Water, vol. 10, no. 12, p. 1866, 2018.

[51] V. Sridhar, P. Modi, M. M. Billah, P. Valayamkunnath, and J. L. Goodall, "Precipitation extremes and flood frequency in a changing climate in southeastern Virginia," JAWRA Journal of the American Water Resources Association, vol. 55, no. 4, pp. 780-799, 2019.

[52] RiverWare, "RiverWare overview," 2015, http://www.riverware. org/riverware/overview.html. 

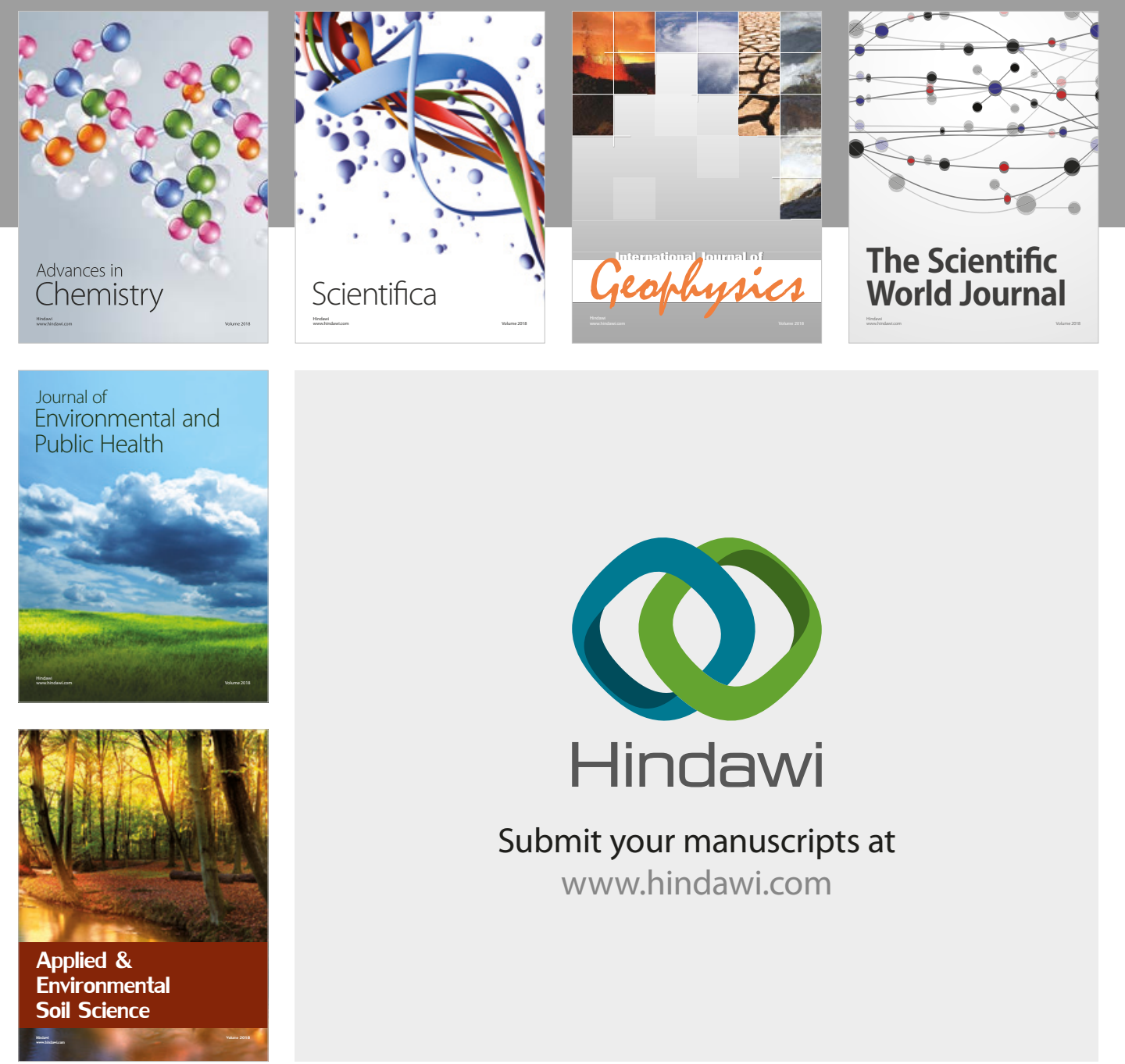

The Scientific

\section{World Journal}
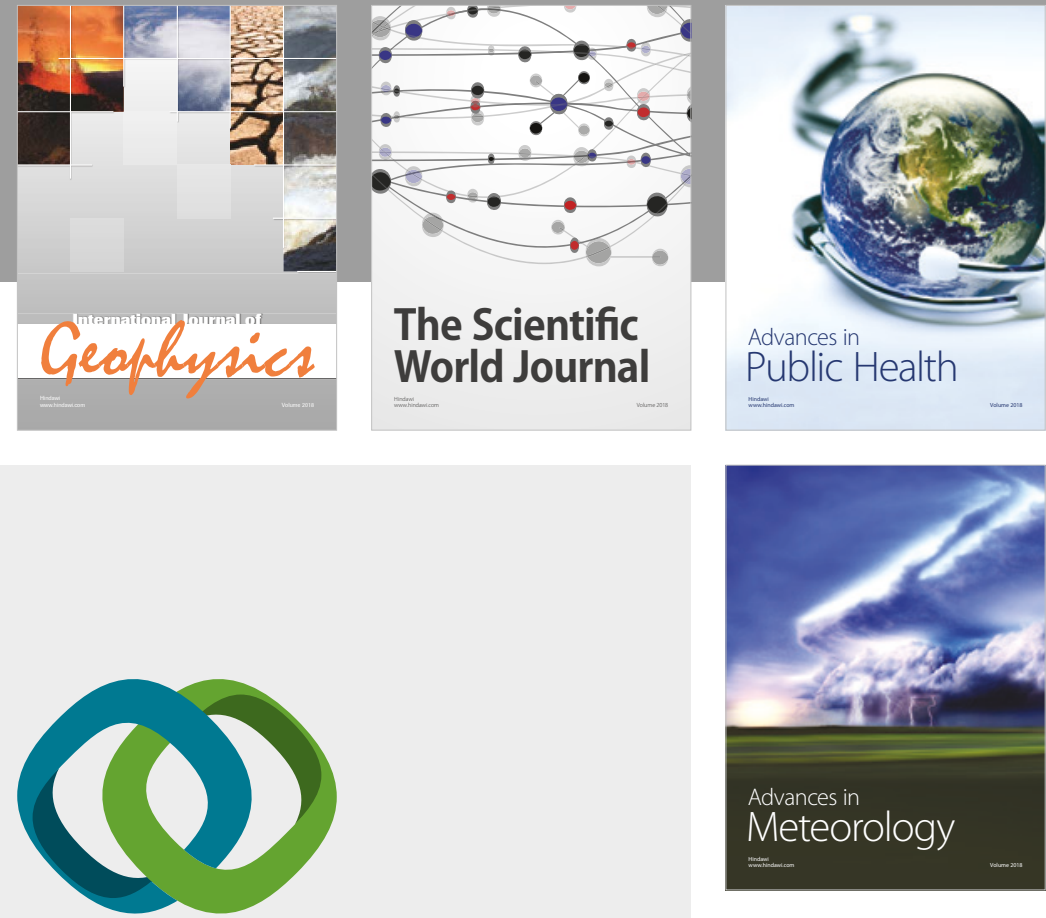

Advan

Public Health

\section{Hindawi}

Submit your manuscripts at

www.hindawi.com
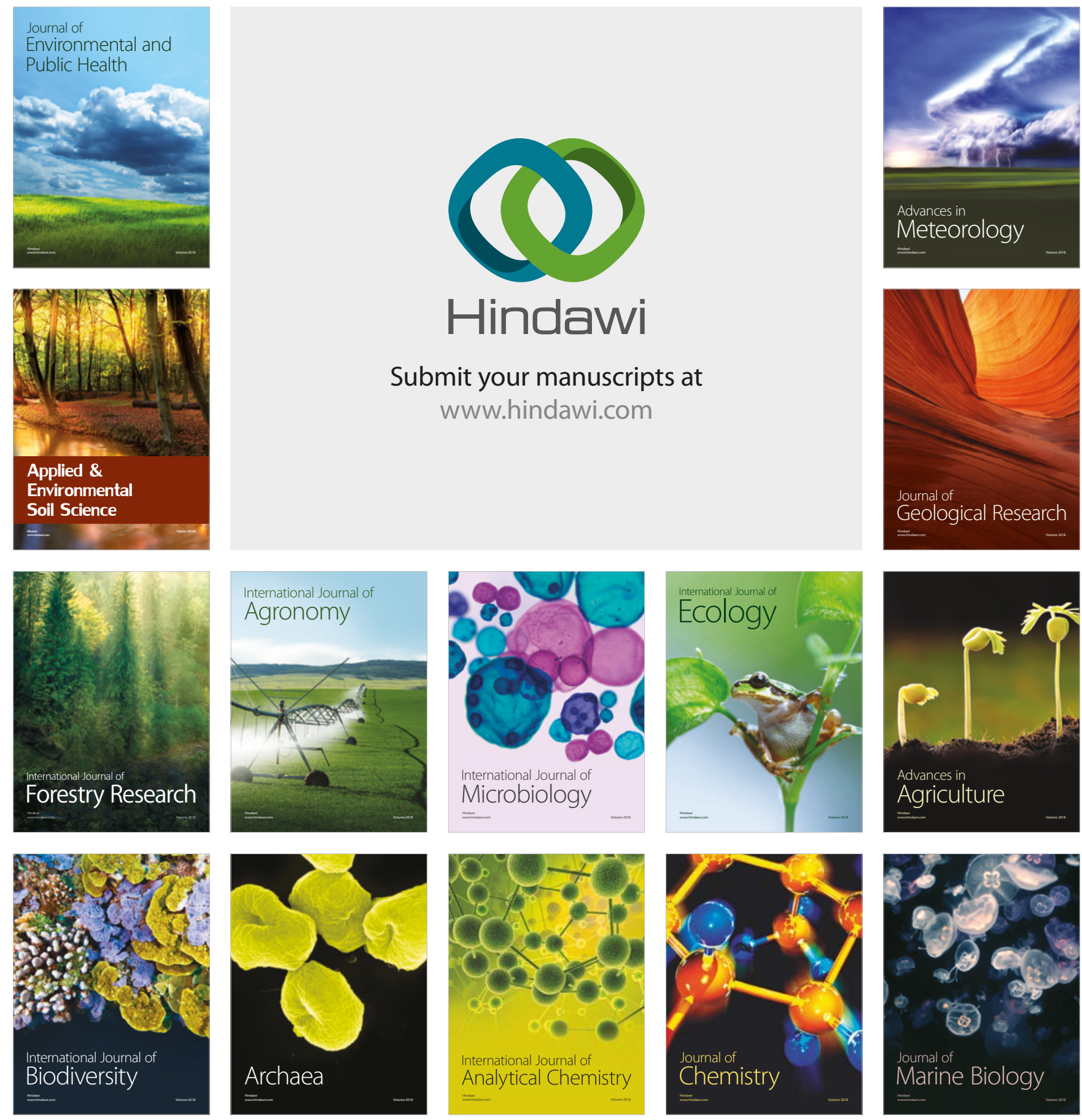